\title{
Secretion of Streptomyces mobaraensis pro-transglutaminase by coryneform bacteria
}

\author{
Hiroshi Itaya • Yoshimi Kikuchi
}

Received: 12 November 2007 /Revised: 19 December 2007 / Accepted: 20 December 2007 / Published online: 25 January 2008

(C) The Author(s) 2008

\begin{abstract}
We previously reported on the secretion of Streptomyces mobaraensis transglutaminase by Corynebacterium glutamicum ATCC13869 (formerly classified as Brevibacterium lactofermentum). In the present work, we investigated whether any other coryneform bacteria showed higher productivity than C. glutamicum ATCC13869. We found that most coryneform species secreted pro-transglutaminase efficiently. Moreover, we confirmed that Corynebacterium ammoniagenes ATCC6872 produced about $2.5 \mathrm{~g} / \mathrm{l}$ pro-transglutaminase over a 71-h period in a jar fermentor. Our findings suggest that some other coryneform bacteria, especially C. ammoniagenes ATCC6872, are potential hosts for industrial scale protein production.
\end{abstract}

\section{Keywords Corynebacterium glutamicum .}

Corynebacterium ammoniagenes . Transglutaminase .

Protein secretion

\section{Introduction}

The secretion of heterologous proteins into culture medium is a potentially useful method of production (Choi and Lee 2004), although the amounts obtained through this approach are generally small. Thus, there remains a need to develop an efficient secretion system for industrial proteins. Streptomyces mobaraensis transglutaminase (TG) has been used in the food industry to modify proteins (Yokoyama

H. Itaya $\cdot$ Y. Kikuchi $(\square)$

Institute of Life Sciences, Ajinomoto Co. Inc.,

1-1 Suzuki-cho, Kawasaki-ku,

Kawasaki 210-8681, Japan

e-mail: yoshimi_kikuchi@ajinomoto.com et al. 2004). It is utilized in binding meat and fish and in gelled food products such as jelly, yogurt, and cheese. Moreover, it has great potential for use in manufacturing the materials found in cosmetics, thermostable microcapsules, and carriers for immobilized enzymes (Yokoyama et al. 2004). However, so far, an efficient production system for TG has been lacking.

A large number of different coryneform bacteria have been isolated from soil, animals, and plants (Liebl 2005). Some are used in biotechnological production processes; for example, Corynebacterium glutamicum and Corynebacterium ammoniagenes are well-known industrial producers of amino acids and nucleotides, respectively (Liebl 2005). C. glutamicum is a Gram-positive, non-sporulating bacterium with about $53.8 \%$ guanine-cytosine (GC) DNA content and its genome has been sequenced (Ikeda and Nakagawa 2003; Kalinowski et al. 2003). This species is extensively used in the industrial production of amino acids, such as glutamate and lysine, which have been applied in human food, animal feed, and pharmaceutical products for several decades (Hermann 2003; Krämer 1994; Liebl 2005). However, there had been only few reports concerning heterologous protein secretion in C. glutamicum (Billman-Jacobe et al. 1995; Liebl et al. 1992; Salim et al. 1997). Recently, we demonstrated that TG could be efficiently secreted in an active form using a signal peptide derived from a cell-surface protein of coryneform bacteria in C. glutamicum ATCC13869 (Date et al. 2003, 2004; Kikuchi et al. 2003). We showed that C. glutamicum ATCC13869 could also secrete an active form of human epidermal growth factor, which consists of 53 amino acid residues, including six cysteine residues that form three disulfide bonds (Date et al. 2006). More recently, it has been shown that the twin-arginine translocation (Tat) pathway, which is a recently detected protein secretion 
pathway, is active in C. glutamicum ATCC13869 and that the Chryseobacterium proteolyticum pro-protein glutaminase, which is not secreted via the Sec pathway in $C$. glutamicum ATCC13869, is efficiently secreted by the Tat pathway (Kikuchi et al. 2006, 2007). These results demonstrate that protein production using C. glutamicum might be useful on an industrial scale. However, little is known about heterologous protein production by other species of coryneform bacteria.

In this report, we show that most other coryneform bacteria also secrete pro-TG efficiently and that $C$. ammoniagenes ATCC6872 is the best producer species, accumulating about $2.5 \mathrm{~g} / 1$ pro-TG over a period of $71 \mathrm{~h}$ in a jar fermentor.

\section{Materials and methods}

Bacterial strains, plasmids, and culture medium

The bacterial strains used are shown in Table 1. The plasmids were as follows: pPSPTG1 (Kikuchi et al. 2003), which contains the $\operatorname{csp} B$ promoter derived from $C$. glutamicum ATCC13869; the CspA signal peptide sequence derived from a cell-surface protein of C. ammoniagenes ATCC6872; and the coding region of pro-TG, derived from $S$. mobaraensis, and pPKPTG1 (Kikuchi et al. 2003), in which the signal peptide for pro-TG secretion

Table 1 Pro-TG accumulation by coryneform bacteria carrying pPSPTG1 in MMTG medium at $30^{\circ} \mathrm{C}$ for $72 \mathrm{~h}$

\begin{tabular}{ll}
\hline Strain & Pro-TG (mg/l) \\
\hline Corynebacterium ammoniagenes ATCC6872 & 454 \\
Corynebacterium glutamicum ATCC13032 & 147 \\
Brevibacterium taipei ATCC13744 & 201 \\
Corynebacterium glutamicum & 66 \\
(Micrococcus glutamicus) ATCC13761 & \\
Brevibacterium roseum ATCC13825 & 269 \\
Corynebacterium glutamicum & 314 \\
(Brevibacterium flavum) ATCC13826 & \\
Corynebacterium herculis ATCC13868 & 54 \\
Corynebacterium glutamicum & 118 \\
(Brevibacterium lactofermentum) ATCC13869 & \\
Corynebacterium acetoacidophilum ATCC13870 & 369 \\
Corynebacterium glutamicum & 391 \\
(Brevibacterium divaricatum) ATCC14020 & \\
Brevibacterium saccharolyticum ATCC14066 & 238 \\
Brevibacterium immariophilium ATCC14068 & 257 \\
Microbacterium ammoniaphilum ATCC15354 \\
Corynebacterium glutamicum \\
(Corynebacterium lilium) ATCC15990 \\
Corynebacterium callunae ATCC15991 \\
Brevibacterium thiogenitalis ATCC19240 \\
\hline
\end{tabular}

is replaced by the CspB signal peptide sequence from $C$. glutamicum ATCC13869. The coryneform bacteria were aerobically grown in $\mathrm{CM} 2 \mathrm{G}$ medium (Kikuchi et al. 2003) at $30^{\circ} \mathrm{C}$ in a shaking test tube. Plasmids were introduced by electroporation with a Gene Pulser (Bio-Rad) using the standard protocol for Corynebacterium species. For pro-TG production in a test tube culture, we used MMTG medium containing $60 \mathrm{~g}$ glucose, $1 \mathrm{~g} \mathrm{MgSO} 4 \cdot 7 \mathrm{H}_{2} \mathrm{O}, 30 \mathrm{~g}\left(\mathrm{NH}_{4}\right)_{2} \mathrm{SO}_{4}$, $1.5 \mathrm{~g} \mathrm{KH}_{2} \mathrm{PO}_{4}, 0.01 \mathrm{~g} \mathrm{FeSO}_{4} \cdot 7 \mathrm{H}_{2} \mathrm{O}, 0.01 \mathrm{~g} \mathrm{MnSO}_{4} \cdot 4 \mathrm{H}_{2} \mathrm{O}$, $450 \mu \mathrm{g}$ thiamine hydrochloride, $450 \mu \mathrm{g}$ biotin, $0.15 \mathrm{~g}$ dl-methionine, and $50 \mathrm{~g} \mathrm{CaCO}_{3}$ per 1 distilled water, adjusted to pH 7.5 (Kikuchi et al. 2003). Kanamycin ( $25 \mathrm{mg} / \mathrm{l}$ ) was added to the culture medium when required.

Jar fermentation

Fermentor growth was carried out in a 1-1 jar fermentor (300 $\mathrm{ml}$ working capacity). Glycerol stock suspensions of bacteria were stored at $-80^{\circ} \mathrm{C}$ in $20 \mathrm{v} / \mathrm{v}$ glycerol. Glycerol stock suspension $(50 \mu \mathrm{l})$ was inoculated into $50 \mathrm{ml} \mathrm{CM} 2 \mathrm{G}$ medium in a 500-ml Sakaguchi flask, and cultured at $27^{\circ} \mathrm{C}$ for $24 \mathrm{~h}$. Then, $15 \mathrm{ml}$ of the culture was inoculated into $300 \mathrm{ml}$ MMTG-J medium containing $120 \mathrm{~g}$ glucose, $1 \mathrm{~g} \mathrm{MgSO}_{4} \cdot 7 \mathrm{H}_{2} \mathrm{O}, 30 \mathrm{~g}\left(\mathrm{NH}_{4}\right)_{2} \mathrm{SO}_{4}, 1.5 \mathrm{~g} \mathrm{KH}_{2} \mathrm{PO}_{4}, 0.01 \mathrm{~g}$ $\mathrm{FeSO}_{4} \cdot 7 \mathrm{H}_{2} \mathrm{O}, 0.01 \mathrm{~g} \mathrm{MnSO}_{4} \cdot 4 \mathrm{H}_{2} \mathrm{O}, 450 \mu \mathrm{g}$ thiamine hydrochloride, $450 \mu \mathrm{g}$ biotin, $0.15 \mathrm{~g}$ dl-methionine, and $0.2 \mathrm{~g}$ total nitrogen of soybean hydrolyzate per 1 distilled water, adjusted to $\mathrm{pH}$ 7.2. The jar fermentor operating conditions were as follows: agitation rate $=600 \mathrm{rpm}$, airflow rate $=1 / 2 \mathrm{vvm}$; temperature $=27^{\circ} \mathrm{C}$. The culture was automatically maintained at $\mathrm{pH} 7.2$ by the controlled addition of ammonia gas with airflow. The glucose concentrations were analyzed using an AS-210 glucose analyzer (Sakura Seiki, Tokyo, Japan), and the optical densities were measured at $625 \mathrm{~nm}$ with a DU640 photometer (Beckman Coulter).

Protein analysis

Sodium dodecyl sulfate-polyacrylamide gel electrophoresis (SDS-PAGE) in a 4-20\% gradient polyacrylamide gel was carried out as described by Laemmli (1970), with Coomassie brilliant blue R-250 staining. The secreted pro-TG was measured by reverse-phase high-performance liquid chromatography, using purified native TG as a standard (Yokoyama et al. 2002). For processing the pro-TG to convert to an active form, the secreted pro-TG in a culture supernatant was incubated with purified SAM-P45 (Suzuki et al. 1997) at $30^{\circ} \mathrm{C}$ for $2 \mathrm{~h}$, at a $100: 1$ ratio of pro-PG to SAM-P45. The purified SAM-P45 was a gift from Dr. S. Taguchi. The active-form TG was purified according to the method described previously (Yokoyama et al. 2002). TG activity was measured by the calorimetric hydroxamate procedure using $\mathrm{N}$-carbobenzoxy-L-glutaminylglycine as 
described previously (Yokoyama et al. 2002). For determining the $N$-terminal amino acid sequence of the pro-TG, after separation by SDS-PAGE, proteins were transferred to polyvinylidene difluoride membrane by electroblotting. The membrane carrying the pro-TG was directly subjected to a gas phase protein sequencer (model PSQ; Shimadzu, Kyoto, Japan) equipped with an in-line amino acid analyzer (model RF-550; Shimadzu) as described previously (Kikuchi et al. 1997).

\section{Results and discussion}

Secretion of pro-TG by coryneform bacteria using $C$. ammoniagenes ATCC6872 CspA signal peptide

We transformed the bacteria listed in Table 1 with pPSPTG1, cultured each transformant in MMTG medium at $30^{\circ} \mathrm{C}$ for $72 \mathrm{~h}$, and then subjected the supernatants to SDS-PAGE. As shown in Fig. 1, each transformant could stably secrete the pro-TG, and high levels of pro-TG with the anticipated molecular weight $(42 \mathrm{kDa})$ were detected in the supernatants for all of the bacteria tested (Table 1). The pro-TG was most efficiently secreted by $C$. ammoniagenes ATCC6872, Corynebacterium acetoacidophilum ATCC13870, C. glutamicum ATCC14020 (formerly classified as Brevibacterium divaricatum), Microbacterium ammoniaphilum ATCC15354, and Corynebacterium callunae ATCC15991.

We tested 16 strains of coryneform bacteria for the secretion of $S$. mobaraensis pro-TG. As shown in Fig. 1 and Table 1, all of the bacteria secreted pro-TG. We have previously shown that the $C$. glutamicum system has two advantages for heterologous protein secretion: a lack of proteolytic activity in C. glutamicum culture supernatants and a small amount of protein secretion by the bacteria themselves (Date et al. 2006; Kikuchi et al. 2003). As a result, the purification of secreted heterologous proteins is relatively easy. From the results shown in Fig. 1, it is clear that the other coryneform bacteria share these advantages for heterologous protein secretion: their culture supernatants contain little endogenous protein and no degradation of pro-TG is detected in the supernatants.

Effect of signal peptide sequence on pro-TG secretion

Next, to investigate whether the secretion efficiency depended on the signal peptide sequence, we examined the effect of using the CspA signal peptide from $C$. ammoniagenes ATCC6872 (Fig. 2a) or the CspB signal peptide from C. glutamicum ATCC13869 (Fig. 2a) for the pro-TG secretion. C. ammoniagenes ATCC6872, C. acetoacidophilum ATCC13870, C. glutamicum ATCC14020, M. ammoniaphilum ATCC15354, and C. callunae a

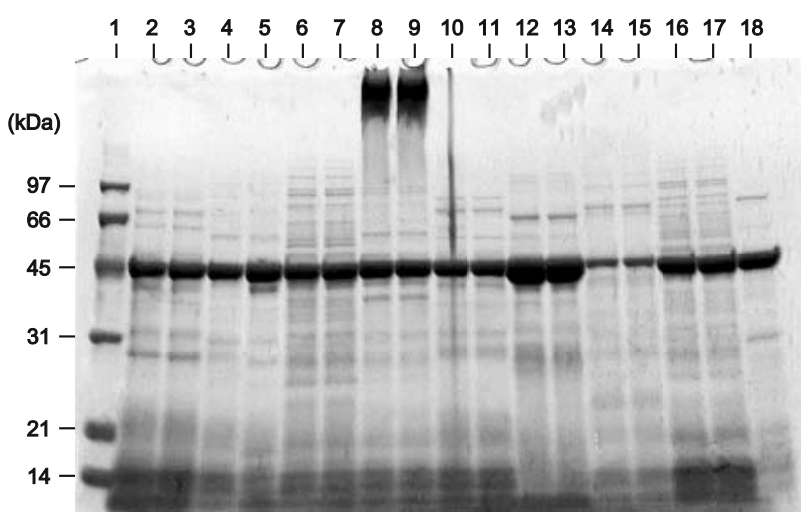

b

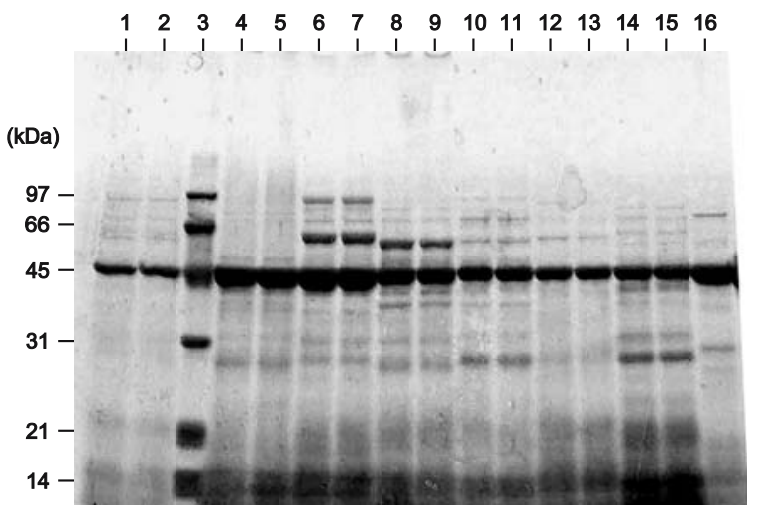

Fig. 1 SDS-PAGE analysis of pro-TG secretion by coryneform bacteria carrying pPSPTG1. Each track contained a 10- $\mu$ l aliquot of supernatant mixed with an equal volume of sample buffer. After electrophoresis, the gel was stained with Coomassie brilliant blue R250. a Lane 1, molecular weight markers; lanes 2 and $3, B$. saccharolyticum ATCC14066; lanes 4 and 5, B. roseum ATCC13825; lanes 6 and 7, B. immariophilium ATCC14068; lanes 8 and 9, C. glutamicum ATCC13826; lanes 10 and 11, C. glutamicum ATCC15990; lanes 12 and 13, C. callunae ATCC15991; lanes 14 and 15, C. herculis ATCC13868; lanes 16 and 17, C. acetoacidophilum ATCC13870; lanes 18, C. ammoniagenes ATCC6872. b Lanes 1 and 2, C. glutamicum ATCC13761; lane 3, molecular weight markers; lanes 4 and 5, C. glutamicum ATCC14020; lanes 6 and 7, M. ammoniaphilum ATCC15354; lanes 8 and 9, B. taipei ATCC13744; lanes 10 and 11, B. thiogenitalis ATCC19240; lanes 12 and 13,C. glutamicum ATCC13869; lanes 14 and 15, C. glutamicum ATCC13032; lane 16, C. ammoniagenes ATCC6872

ATCC15991 could efficiently secrete the pro-TG using the CspA signal peptide from $C$. ammoniagenes ATC C6872 in this study. These strains and C. glutamicum ATCC13869 were transformed with pPKPTG1 harboring the CspB signal peptide from C. glutamicum ATCC13869. As shown in Fig. 2b, the substitution of the CspB signal peptide had little effect on pro-TG accumulation in $C$. acetoacidophilum ATCC13870, C. glutamicum ATC C14020, and M. ammoniaphilum ATCC15354. However, in C. callunae ATCC15991, the pro-TG accumulation $(403 \mathrm{mg} / \mathrm{l})$ was approximately halved $(746 \mathrm{mg} / \mathrm{l})$ while in 
Fig. 2 Effect of signal peptide sequence on pro-TG secretion in coryneform bacteria. a Amino acid sequence alignment of $C$. ammoniagenes CspA signal peptide and C. glutamicum CspB signal peptide using Vector NTI software. Identical and similar residues are shown on black and gray backgrounds, respectively. b Accumulation of secreted pro-TG by coryneform bacteria carrying pPSPTG1 or pPKPTG1. The solid bars indicate pro-TG accumulation using the CspA signal peptide from $C$. ammoniagenes ATCC6872, and the open bars indicate pro-TG accumulation using the $\mathrm{CspB}$ signal peptide from C. glutamicum ATCC13869 a

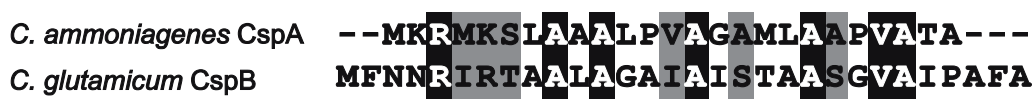

b

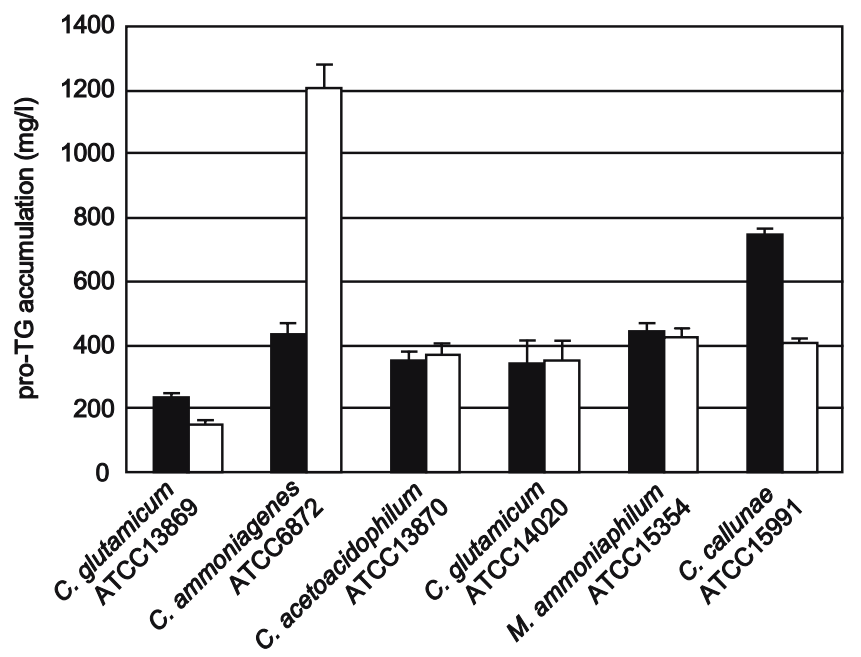

C. ammoniagenes ATCC6872, it was about 2.8-fold higher.

The amount of pro-TG accumulation by C. ammoniagenes ATCC6872 using the CspB signal peptide from $C$. glutamicum ATCC13869 was about 2.8-fold higher than with its own CspA signal peptide (Fig. 2b). Interestingly, the difference between the effects of the two signal peptides was the opposite in C. glutamicum ATCC13869: the amount of pro-TG accumulation using the CspA signal peptide from $C$. ammoniagenes ATCC6872 was about 1.5fold higher than with the $\mathrm{CspB}$ signal peptide from $C$. glutamicum ATCC13869 (Kikuchi et al. 2003). We found the same to be true for all of the heterologous proteins examined so far (data not shown). The reason for the differing effects of these signal peptides is unclear.

Cultivation of $C$. ammoniagenes ATCC6872 carrying pPKPTG1 in a jar fermentor

As C. ammoniagenes ATCC6872 carrying pPKPTG1 was the best producer strain in our study, we subjected it to a fermentation test in a jar fermentor under the conditions described in the "Materials and methods" section. The MMTG-J medium contained $120 \mathrm{~g} / \mathrm{l}$ glucose; after the consumption of glucose for $71 \mathrm{~h}$ under these conditions, the optical density at $625 \mathrm{~nm}$ reached approximately 140 , and the dry cell concentration was approximately $50 \mathrm{~g} / \mathrm{l}$. During the exponential growth phase, little pro-TG accumulated in the culture supernatant; however, the rate of accumulation increased linearly after entry into the stationary phase, and approximately $2.5 \mathrm{~g} / 1$ pro-TG was produced (Fig. 3). The $N$-terminal amino acid of the secreted pro-TG was Asp, as in native pro-TG (Kikuchi et al. 2003), demonstrating that the CspB signal peptide had been correctly processed in C. ammoniagenes ATCC6872. We then incubated the culture supernatant with purified SAM$\mathrm{P} 45$, which is a subtilisin-like protease from Streptomyces albogriseolus, for $2 \mathrm{~h}$ at a 100:1 ratio of pro-TG to SAM$\mathrm{P} 45$ in order to process the pro-domain (Kikuchi et al. 2003). The pro-TG secreted by $C$. ammoniagenes

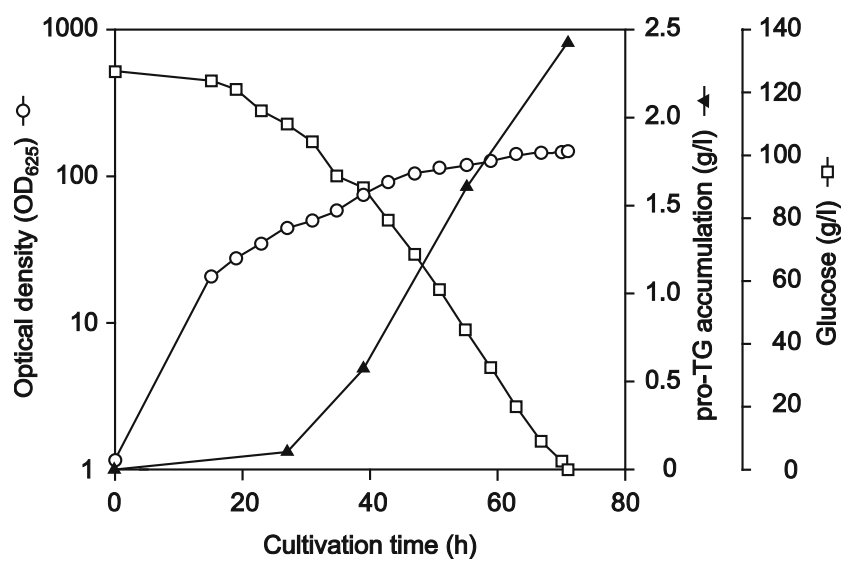

Fig. 3 Jar fermentation experiment employing $C$. ammoniagenes ATCC6872 carrying pPKPTG1. Growth (optical density at $625 \mathrm{~nm}$ ), glucose concentration, and pro-TG accumulation are indicated by open circles, open squares, and closed triangles, respectively 
ATCC6872 carrying pPKPTG1 was cleaved by purified SAM-P45 to the C-side of 41-Ser of the pro-domain and converted to an active form and the conversion yield of this enzymatic process was approximately 100\%. The specific activity of the purified active-form TG, with additional Phe-Arg-Ala-Pro residues, was similar to that of the native TG (about $23 \mathrm{U} / \mathrm{mg}$; Kikuchi et al. 2003).

The results of the fermentation experiments in the 1-1 jar fermentors showed that the pro-TG secreted by $C$. ammoniagenes ATCC6872 was correctly folded. Thus, protein production using $C$. ammoniagenes ATCC6872 could be useful for industrial scale protein production.

Acknowledgements We are grateful to Dr. S. Taguchi for his kind gift of purified SAM-P45. We also thank Dr. T. Mannen for helping in preparation of this manuscript.

Open Access This article is distributed under the terms of the Creative Commons Attribution Noncommercial License which permits any noncommercial use, distribution, and reproduction in any medium, provided the original author(s) and source are credited.

\section{References}

Billman-Jacobe H, Wang L, Kortt A, Stewart D, Radford A (1995) Expression and secretion of heterologous proteases by Corynebacterium glutamicum. Appl Environ Microbiol 61: $1610-1613$

Choi JH, Lee SY (2004) Secretory and extracellular production of recombinant proteins using Escherichia coli. Appl Microbiol Biotechnol 64:625-635

Date M, Yokoyama K, Umezawa Y, Matsui H, Kikuchi Y (2003) Production of native-type Streptoverticillium mobaraense transglutaminase in Corynebacterium glutamicum. Appl Environ Microbiol 69:3011-3014

Date M, Yokoyama K, Umezawa Y, Matsui H, Kikuchi Y (2004) High level expression of Streptomyces mobaraensis transglutaminase in Corynebacterium glutamicum using a chimeric pro-region from Streptomyces cinnamoneus transglutaminase. J Biotechnol 110:219-226

Date M, Yokoyama K, Umezawa Y, Matsui H, Kikuchi Y (2006) Secretion of human epidermal growth factor by Corynebacterium glutamicum. Lett Appl Microbiol 42:66-70

Ikeda M, Nakagawa S (2003) The Corynebacterium glutamicum genome: features and impacts on biotechnological processes. Appl Microbiol Biotechnol 62:99-109
Hermann T (2003) Industrial production of amino acids by coryneform bacteria. J Biotechnol 104:155-172

Kalinowski J, Bathe B, Bartels D, Bischoff N, Bott M, Burkovski A, Dusch N, Eggeling L, Eikmanns BJ, Gaigalat L, Goesmann A, Hartmann M, Huthmacher K, Krämer R, Linke B, McHardy AC, Meyer F, Möckel B, Pfefferle W, Pühler A, Rey DA, Rückert C, Rupp O, Sahm H, Wendisch VF, Wiegräbe I, Tauch A (2003) The complete Corynebacterium glutamicum ATCC 13032 genome sequence and its impact on the production of L-aspartate-derived amino acids and vitamins. J Biotechnol 104:5-25

Kikuchi Y, Kojima H, Tanaka T, Takatsuka Y, Kamio Y (1997) Characterization of a second lysine decarboxylase isolated from Escherichia coli. J Bacteriol 179:4486-4492

Kikuchi Y, Date M, Yokoyama K, Umezawa Y, Matsui H (2003) Secretion of active-form Streptoverticillium mobaraense transglutaminase by Corynebacterium glutamicum: processing of the pro-domain by a co-secreted subtilisin-like protease from Streptomyces albogriseolus. Appl Environ Microbiol 69: 358-366

Kikuchi Y, Date M, Itaya H, Matsui K, Wu LF (2006) Functional analysis of the twin-arginine translocation pathway in Corynebacterium glutamicum ATCC13869. Appl Environ Microbiol 72:7183-7192

Kikuchi Y, Itaya H, Date M, Matsui K, Wu LF (2007) Production of Chryseobacterium proteolyticum protein-glutaminase using the twin-arginine translocation pathway in Corynebacterium glutamicum. Appl Microbiol Biotechnol (in press)

Krämer R (1994) Secretion of amino acids by bacteria: physiology and mechanism. FEMS Microbiol Rev 12:75-94

Laemmli UK (1970) Cleavage of structural proteins during the assembly of the head of bacteriophage T4. Nature 227: $680-685$

Liebl W (2005) Corynebacterium taxonomy. In: Eggeling L, Bott M (eds) Handbook of Corynebacterium glutamicum. CRC Press LLC, Boca Raton, pp 9-34

Liebl W, Sinskey AJ, Schleifer KH (1992) Expression, secretion, and processing of staphylococcal nuclease by Corynebacterium glutamicum. J Bacteriol 174:1854-1861

Salim K, Haedens V, Content J, Leblon G, Huygen K (1997) Heterologous expression of the Mycobacterium tuberculosis gene encoding antigen 85A in Corynebacterium glutamicum. Appl Environ Microbiol 63:4392-4400

Suzuki M, Taguchi S, Yamada S, Kojima S, Miura K, Momose H (1997) A novel member of the subtilisin-like protease family from Streptomyces albogriseolus. J Bacteriol 179:430-438

Yokoyama K, Ono K, Ohtsuka T, Nakamura N, Seguro K, Ejima D (2002) In vitro refolding process of urea-denatured microbial transglutaminase without pro-peptide sequence. Protein Expr Purif 26:329-335

Yokoyama K, Nio N, Kikuchi Y (2004) Properties and applications of microbial transglutaminase. Appl Microbiol Biotechnol $64: 447-454$ 